\title{
Environmental awareness and vulnerability in the Yellow River Delta: Results based on a comprehensive household survey
}

\author{
Michel L. Wolters ${ }^{a,}{ }^{*}$, Zhongchang Sun ${ }^{\mathrm{b}}$, Chong Huang ${ }^{\mathrm{c}}$, Claudia Kuenzer ${ }^{\mathrm{a}}$ \\ a German Aerospace Center (DLR), Earth Observation Center (EOC), German Remote Sensing Data Center (DFD), 82234 Weßling, Germany \\ ${ }^{\mathrm{b}}$ Laboratory of Digital Earth Science, Institute of Remote Sensing and Digital Earth, Chinese Academy of Sciences (CAS), Beijing 100094, China \\ c State Key Laboratory of Resource and Environment Information System, Institute of Geographic Sciences and Natural Resources Research, Chinese \\ Academy of Sciences (CAS), Beijing 100101, China
}

\section{A R T I C L E I N F O}

\section{Article history:}

Received 24 July 2015

Received in revised form

22 October 2015

Accepted 12 November 2015

Available online 1 December 2015

\section{Keywords:}

Yellow River Delta

Household survey

Social

Vulnerability

\begin{abstract}
A B S T R A C T
In this paper, we present the results of a comprehensive survey concerning environmental awareness and vulnerability, conducted in October 2013 in the Yellow River Delta, China. The purpose of this survey is to provide insight to the vulnerability of rural households and their livelihoods to internal and external threats, such as flooding, oil spills, droughts, erosion, and salinization. Education level, awareness, opinions regarding pollution and available public utilities and facilities are also polled. Specific questions regarding agriculture and aquaculture activities are included. It is the most comprehensive questionnaire regarding social vulnerability in the area to date, with 93 households interviewed with the aid of an interpreter. The results show that the respondents generally have a low education; many earn below minimum wage for the area, and are not aware of global processes of climate variability and sea level rise. Cotton and maize are the predominant agriculture crops farmed in the area, while ground salinization is a major threat to agriculture. The results of this survey can be used in a follow up study in conjunction with a separate spatial data analysis (e.g. earth observation, census) to assess the social vulnerability in the Yellow River Delta in a spatially representative fashion.
\end{abstract}

๑) 2015 Elsevier Ltd. All rights reserved.

\section{Introduction}

Coastal river deltas are alluvial deposits where rivers meet the sea, and are intricate systems where its ecologic, social, and economic components coexist (Wolters and Kuenzer, 2015). Coastal river deltas are rich in natural resources, such as fresh water, sediment flows, fertile lands, and fossil fuel deposits, as well as ecologically diverse areas such as wetlands, saltmarshes, and mangroves. Over time, this has attracted humans, which have populated, urbanized, and industrialized deltas, using the ecological rich areas and natural resources for economic development. Water corridors are widened, water flows diverted, and land is reclaimed which allows for more economic and social development (Anthony, 2014; Kuenzer and Renaud, 2012; Overeem and Syvitski, 2009; Renaud et al., 2013). As a result, the interests of the ecologic, social, and economic components often collide, e.g. industrial pollution affects the ecologic and social components, and limited

\footnotetext{
* Corresponding author.

E-mail address: michel.wolters@dlr.de (M.L. Wolters).
}

resources result in allocation quotas affecting components or areas that receive insufficient natural resources, such as usable water (Jiang, 2009). Meanwhile, external processes such as climate variability and sea level rise (SLR) affect the delta and its components in different fashions and by varying degrees, depending on the health and coping capacity of the river delta's components (Wolters and Kuenzer, 2015). If no action is taken to reduce vulnerability of river delta's components, and coping capacity decreases, deltas and their components could irreversibly degrade when exposed to adverse impacts (Renaud et al., 2013).

A vulnerability study, which assesses "the likelihood of a system or system component to experience harm due to exposure to a hazard, perturbation, or stressor" (Turner et al., 2003) aids in giving stakeholders and policy makers more insight in the weaknesses in the river delta. Household surveys are often used to gauge social vulnerability, based on the standard of living, livelihood, available facilities, awareness of threats, and opinions regarding threats, as household surveys reveal this information in a more representative fashion than e.g. census or earth observation data. Examples of studies that assess vulnerability through household surveys in river deltas are IMHEN et al. (2011) in the Mekong Delta, and Wang et al. 
(2012) in the Yangtze River Delta Mmom and Aifesehi (2013) in the Niger Delta, and Wilk and Kgathi (2007) in the inland Okavango Delta. By investigating the level of awareness causation of peoples actions (e.g. human waste disposal), and value of ecosystem services value (e.g. mangroves) can be used to estimate vulnerability of ecologic components in deltas (Kuenzer and Quoc Vo, 2013; Quoc Vo et al., 2015). Mitigation efforts such as legislation or awareness campaigns can be proposed and implemented to increase the awareness of repercussions of people's actions, and global processes, in order to reduce the social vulnerability.

\subsection{Study area}

The Yellow River Delta is a coastal plain where the Yellow River meets the Bohai Sea. It is located inside the Dongying prefectural city, Shandong Province, China $\left(37^{\circ} 44^{\prime} \mathrm{N}, 118^{\circ} 42^{\prime} \mathrm{E}\right.$, see also Fig. 1 ). The prefectural city is approximately $7500 \mathrm{~km}^{2}$ in size, and has an estimated population (2012) of $1.85 \mathrm{M}$ inhabitants, of which approximately $1.05 \mathrm{M}$ live in rural areas (National Bureau of Statistics of China (2013b)). The delta is a highly dynamic area, which has seen rapid urban and industrial development (e.g. the cities of Dongying, Kenli, Hekou, the Dongying Harbor and Industrial area) (Ottinger et al., 2013), especially after the discovery of the Shengli Oil Field, China's second largest, in the 1960's (Kuenzer
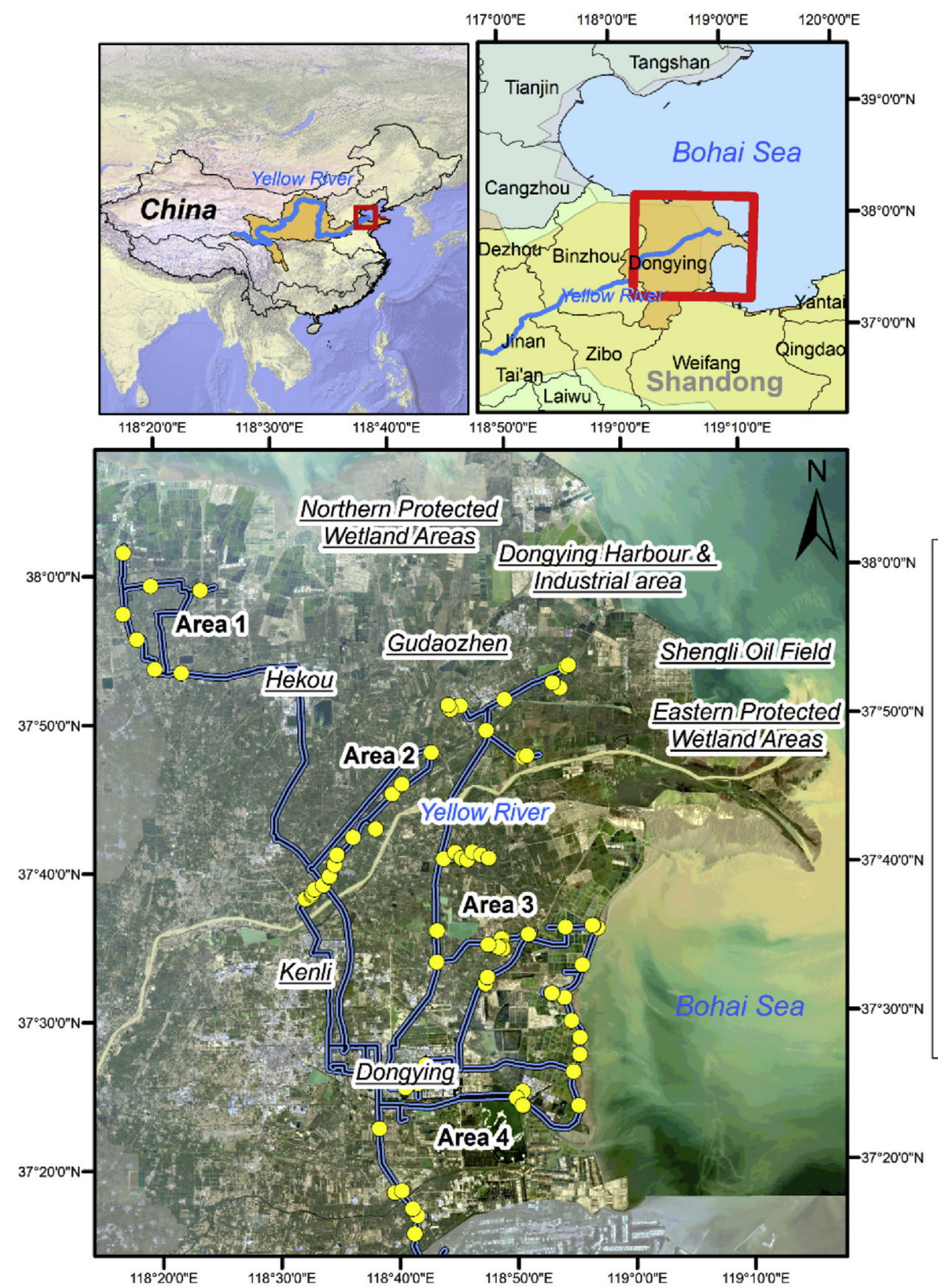

\section{Legend}

Bohai Sea Sea name

Yellow River River name

Dongying District name

Shandong Province name

China Country name

Area 1 Area of interest

Gudaozhen Other places of interest

Questionnaire location

$=\begin{aligned} & \text { Research team } \\ & \text { tracks }\end{aligned}$

Background: Landsat 8, 5 October 2013 Coordinate System: GCS WGS 1984 Datum: WGS 1984 Units: Degree

20 Kilometers

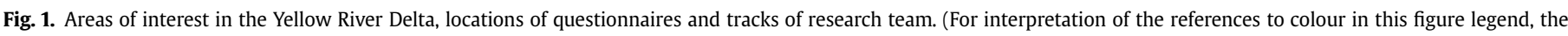
reader is referred to the web version of this article.) 
et al., 2014). The fast economic development led to rapid changes in the Yellow River Delta, such as upgrades to the road infrastructure, seawall and levee construction, to accommodate and protect economic areas (Kuenzer et al., 2015). The Yellow River itself has undergone significant redirections in the past, which have altered the accretion and erosion rates along different parts of the shoreline, affecting the usability of coastal ecological, social, and economic areas. This is exacerbated by SLR, ground subsidence, and salinization (a result of poor ground water management) (Bi et al., 2014; Kuenzer et al., 2014; Overeem and Syvitski, 2009; Xu, 2008). Meanwhile, the Yellow River Delta is home to agriculture and aquaculture activities, which ensures the livelihoods of the rural population in villages throughout the delta. The livelihoods of these people are threatened by the aforementioned industrial and urban developments, in the form of increased air, soil, and water pollution, decreasing usable land, and water quotas (Guobin et al., 2004; Xu et al., 2004). Additionally, factors such as climate (droughts and pluvial floods), resource exhaustion or limitation (decreasing soil usability due to agriculture intensification, salinization, water and soil pollution, ground water depletion), and unequal distribution of economic development (such as access to health services or housing quality, see Figs. 2A and 3) increase the vulnerability of the rural population. The Yellow River itself is also highly polluted from upstream industry and agriculture, while water and sediment influx is constrained due to upstream dam construction and water use (Berry, 2012; Xu et al., 2004). It is observed in the field by the authors prior and during this research that there are major developments ongoing (such as soil revitalization efforts, reconstruction of villages) aimed to decrease the social vulnerability and improving the living standards of the rural population, as can be seen in Fig. 3.

\subsection{Research goal}

The goal of this research is to assess the vulnerability of the rural population from the aforementioned internal and external processes, if they are aware of local and global processes and potential threats to their livelihood, and to ascertain whether the rural population has access to public works, facilities, and utilities. Data considering the vulnerability to hazards of local rural populations and their livelihoods is sparse or non-existent in the Yellow River Delta. Therefore the purpose of the questionnaire is exploratory, providing results and insights that may be used for future questionnaires about vulnerability in the Yellow River Delta.

\section{Questionnaire development and methodology}

Using the aforementioned background information available about the Yellow River Delta considering external and internal threats, we developed a questionnaire. The survey also focuses on some of the general properties of the rural population, such as job, income, age, health insurance, education level, and if respondents have access to public works (trash disposal systems), facilities (infrastructure, hospitals) and utility connections. These factors also serve as an indicator of the vulnerability of the respondents, e.g. respondents with a low income and no health insurance or access to hospitals are more vulnerable to industrial incidents and natural threats, since they cannot seek or afford medical treatment. The survey is divided into several sections for convenience and overview of the interviewer and interviewee, where each section focuses on a specific aspect. Section 1 asks about general properties of the respondents, such as income, age, health insurance, and education level. The second section goes in depth with questions regarding access to public works, facilities, and utilities (water, electricity, medical care, transportation etc.). Section 3 and 4 focus on specific threats the local population might suffer from, namely flood and erosion (3), and chemical or oil spills (4). Section 5 is dedicated to aspects of agri- and aquaculture activities among the rural population, considering the large amounts of farmlands in the Yellow River Delta. This section asks about crops and livestock farmed, irrigation methods used, and opinions about drought events. Finally, section 6 focuses on the opinions of the interviewees related to desired place of living in relation to hazardous areas, alternatives in case of evacuation, and general concerns of the interviewees. In total, the survey contains 56 questions, of which 41 are multiple choice, single answer questions; 8 multiple choice, multiple answer; and 7 are open answer (and afterwards categorized by the interpreter) questions.

\subsection{Sample size, area of interest, and sampling method}

Calculating the appropriate sample size has been done using the Yamane formula (Yamane (1967) after Israel (1992) and Kuenzer and Quoc Vo (2013)). The average household size in Shandong in 2012 is 3.02 people National Bureau of Statistics of China (2013a), which is used to estimate that there are approximately $358 \mathrm{~K}$ rural households in Dongying prefectural city. The Dongying prefectural city contains 5 administrative subdivisions (municipal level). While total population numbers are available for each administrative subdivision (with no discrimination between rural and urban populations), these numbers do not provide accurate population
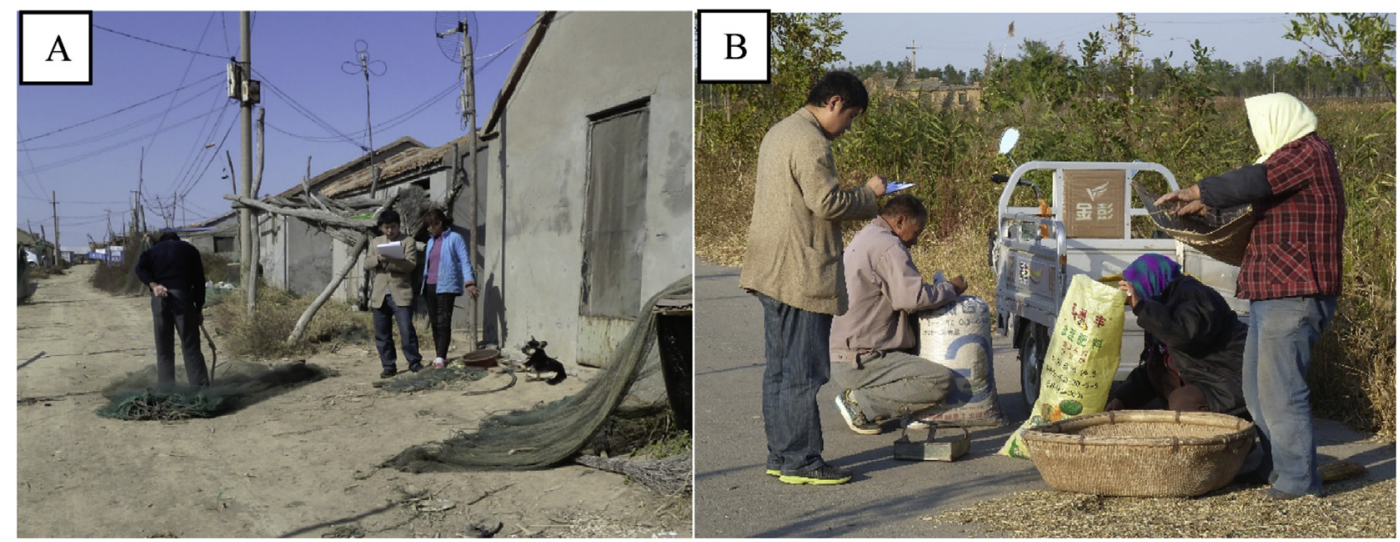

Fig. 2. Impressions of the survey situation. A: interviewing locals in a fishing settlement. B: interviewing farmers. 

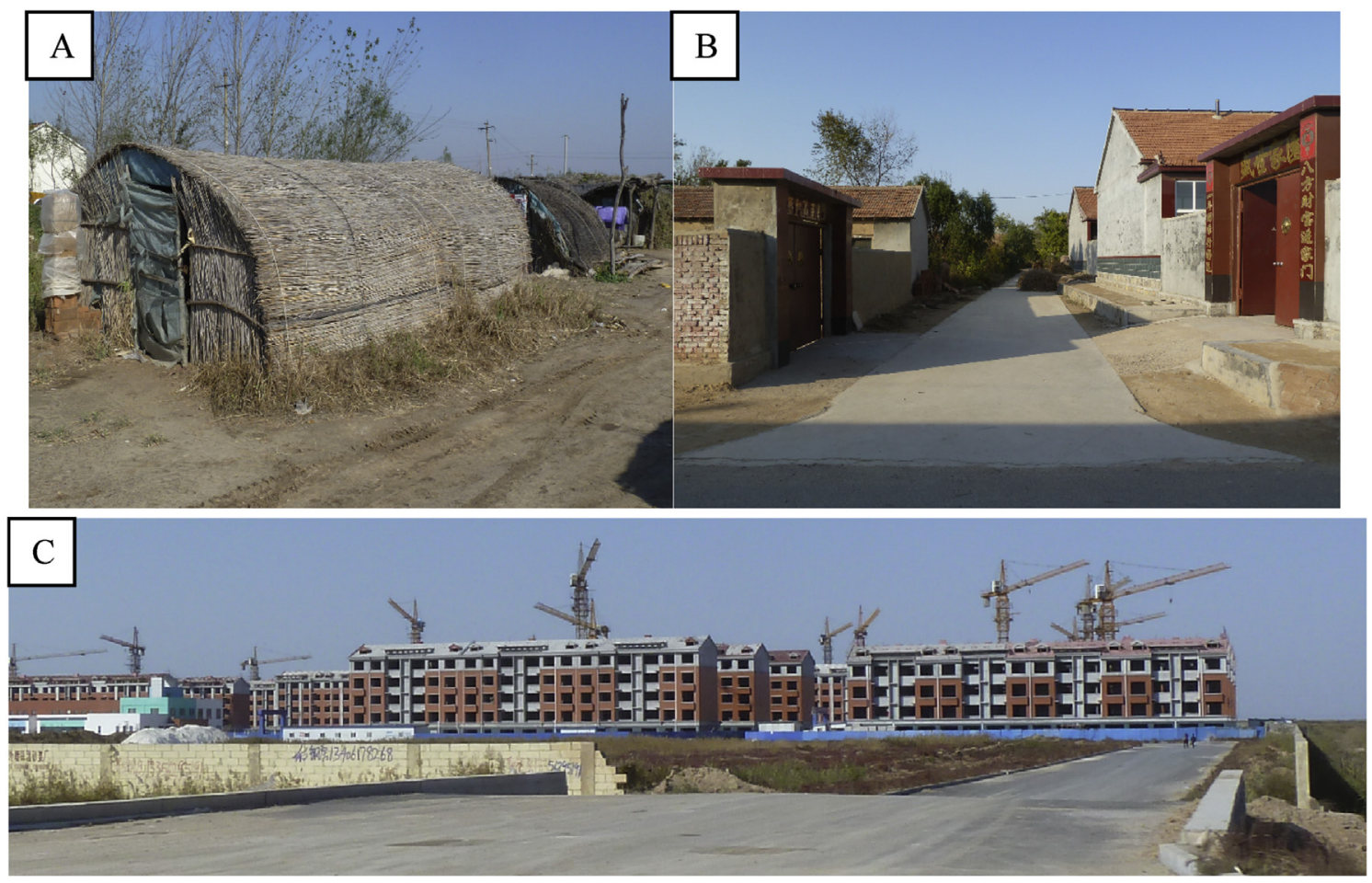

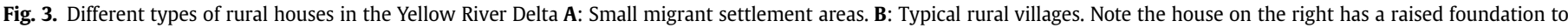
provide protection against pluvial floods. C: New urban developments constructed for the rural population.

statistics for the area of interest alone as the area of interest intersects all subdivisions. Using a confidence level of $95 \%$ and a maximum margin of error of 10\%, 100 samples (households) are necessary to achieve a usable result, using the assumption that there are at least more than $15 \mathrm{~K}$ households in the area of interest. See also equation (1):

$n=\frac{N}{1+N(e)^{2}}$

where: $\mathrm{n}=$ samples needed, $\mathrm{N}=$ sample population, $\mathrm{e}=$ margin of error.

This household survey however has interviewed 93 households, which is lower, though deemed sufficient for the exploratory goal of this survey. The sampling method is based on the convenience of the interview team, taking into account the accessibility of the area (condition and existence of road infrastructure), the opportunity of conducting the interview (willingness of potential respondents), and time limitations due to the size of the river delta and traveling between village clusters with a sedan. The base vantage point of the research team was Dongying. The household survey was conducted in October 2013 over a 6 day period. Each interview takes around 15-30 min, and is completed with the support of a local Chinese to English interpreter (see Fig. 2 for impressions). To determine the areas of interest in the study area where the household surveys would be conducted, data such as Google Earth, and Land Use Land Cover (LULC) datasets as produced by Ottinger et al. (2013). There were no detailed (and non-distorted) road vector maps available of the study area at the time of the questionnaire. Farming and fishing villages with rural population are clustered in several areas in the delta, while other areas do not have village clusters. The areas without village clusters are the Shengli Oil Field, the northern Dongying Harbor with its surrounding chemical plants and industrial pools, the protected wetland areas in the northern and eastern parts of the delta, as well as the urban areas of Dongying, Kenli, Hekou, and Gudouzhen. The areas of interest where the survey is focused on are determined to be (marked in Fig. 1):

1. The northern area of the delta, where major erosion events have occurred due to the redirections of the Yellow River,

2. The area along the course of the Yellow River, where there are many agriculture farms and rural villages,

3. The east coast of the Yellow River Delta where many aquaculture activities, as well as fishing villages, are located, and are protected by a sea wall,

4. The area south-east of Dongying city where agricultural areas and villages are alternated with heavy industry. A bird resort, fishing harbor, and energy plant are also located in this area.

\subsection{Results analysis methodology}

The questionnaire results are collected, compiled, sorted and categorized in Microsoft Excel. Through cross question analysis, we produced a variety of charts and tables which are presented below. Deeper investigation of the questionnaire results, such as spatial analyses based on the questionnaire, is not possible in this study due to the relative small number of respondents $(n=93)$.

\section{Results}

\subsection{Income, education, and occupation}

From section 1 of the household survey (demographic questions), the following results could be obtained. $57 \%$ of the respondents are male, the rest female. The occupation of the respondents are $13 \%$ fishermen, $1 \%$ oil worker, $1 \%$ farmer, $72 \%$ manager, $3 \%$ laborer, $6 \%$ student, and 3\% unemployed. It should be 
noted that while multiple answers were possible, respondents chose to only provide one answer. When asked about the total monthly income of the household of the respondent, it is observed that a slight majority (51\%, see Fig. $4 \mathrm{~A}$ ) of the households earn under 3000 CNY (478 USD, February 2015 conversion) per month. The mean monthly household income of the respondents is 3644 CNY (581 USD), above the 2014 minimum monthly wage of 1380 CNY (222 USD) (Wageindicator, 2014) per person in Dongying prefectural city, Shandong Province, if assumed that households generally have 2 providers. However, a majority of households earn below 3000 CNY per month, as can be seen in Fig. 4A, with $18 \%$ of the respondents indicating they earn less than $1000 \mathrm{CNY}$. When looking at the respondents' education, we observe that more than $96 \%$ has not achieved more than a high school education, with $43 \%$ only having a middle school education, $25 \%$ of the respondents not having more than an elementary education, and $14 \%$ not having received any education. See also Fig. 4B.

\subsection{Household access to public works, facilities, and utilities}

Socio-economic vulnerability is not only determined by the type and frequency of hazards to which the rural population is exposed. Migrants, due to social exclusion and government policy, have a relatively higher rate of vulnerability due to lack of opportunities in the job market, health problems, and restricted access to the social security system (Wang et al., 2012). We have included a question regarding the migrant status of the respondents. Of all respondents, only $18 \%$ have answered that they do not originally come from the Yellow River Delta.

The access to facilities is a significant determinant of vulnerability (e.g. a family with no electricity and living in a loam hut, is more vulnerable than a family living in a newly built suburban style home with access to communication facilities). Hence, the survey includes a set of questions related to the facilities the rural households have access to. This study considers electricity, water, access to healthcare facilities, and waste management as basic facilities. The results show that all respondents have access to electricity (although $7 \%$ of the respondents rely on solar panels, as they live in boats). Access to clean fresh water is an important aspect to the health of rural households. The Yellow River water quality is very poor, while the water quantity is also steadily decreasing ( $\mathrm{Wu}$ and Xia, 2014). Due to the extraction of oil and the presence of large geochemical factories, the water from groundwater wells may be unhealthy for consumption. The results of the questionnaire show that a large majority (89\%) has access to tap water as is supplied to them by a water company. The rest of the respondents receive their drinking water from surface waters $(8 \%)$, or underground water wells (3\%). Furthermore, $16 \%$ of the respondents replied that they have experienced drinking water shortages. All of these indicated that they are supplied with water by a water company. The great majority indicated not to have been affected by water shortages (81\%), while 3\% did not answer the question. Respondents were also asked whether they boil the water they drink before consumption; $97 \%$ of the respondents do so. Waste management is important, as a polluted environment leaves inhabitants at risk to disease (e.g. by pollutants that are re-introduced to humans due to consumption of polluted foods). $49 \%$ of the interviewees use government waste collection points, however $46 \%$ of the inhabitants simply discard their waste or burn it. $5 \%$ of the respondents did not answer this question (Fig. 5A).

The respondents were further asked what kind of transportation facilities they have, as different forms of transport allow for faster evacuation in case of a disaster or incident. The results are classified to indicate what the 'level' of mode of transport is (e.g. motorized/ motorless/none). $1 \%$ of all respondents indicated that they have no transport capabilities. 9\% of the respondents (fishermen) have indicated that a boat is their only form of transport. Interviewees who have only non-motorized forms of land transport (bikes) make up $22 \%$ of the respondents, while $26 \%$ of the respondents indicated they have motorized 2 wheel capabilities. 34\% of the respondents possess a car or comparable transportation option (5\% of the respondents provided no response).

Access to communication facilities helps the rural population stay informed about possible calamities (Wang et al., 2012). 98\% of the respondents have indicated they have a TV or radio set, while $95 \%$ of the respondents have a mobile phone. $39 \%$ of the interviewees have access to the Internet.

In case a rural inhabitant gets sick or is involved in an accident, access to health facilities is critical. The survey inquires both to the presence of health facilities in nearby villages where the respondents live, and whether the respondent is covered by healthcare. $50 \%$ of the respondents mentioned that there is a clinic in their village, $4 \%$ a hospital. $21 \%$ of the interviewees answered that there are no health facilities nearby, while another $21 \%$ did not know where to find any health facilities. 3\% of the respondents did not answer. As for health insurance, 84\% (Fig. 5B) of the respondents answered that they have health care coverage. It seems that this is not related to the migrant status of the respondent, since only $26 \%$ $(n=4)$ of this group indicated that they are migrants.

When a catastrophic disaster occurs wherein households suffer loss of livelihood, have to be (permanently) evacuated, or both, refuge at other members of the family as well as having job alternatives may be useful. The results of the survey have shown that only about a third have family members with whom they could find refuge (see Fig. 6), while only $30 \%$ of the respondents have possible job alternatives. $55 \%$ of all respondents do not have family or job.

alternatives to rely on. When comparing the results of these questions with migrants $(n=17)$ vs. locals $(n=76)$, we can see that a larger percentage of the locals have no family ( $78 \% \mathrm{vs} .17 \%)$ or job alternatives ( $76 \%$ vs $41 \%$ ) to fall back on.
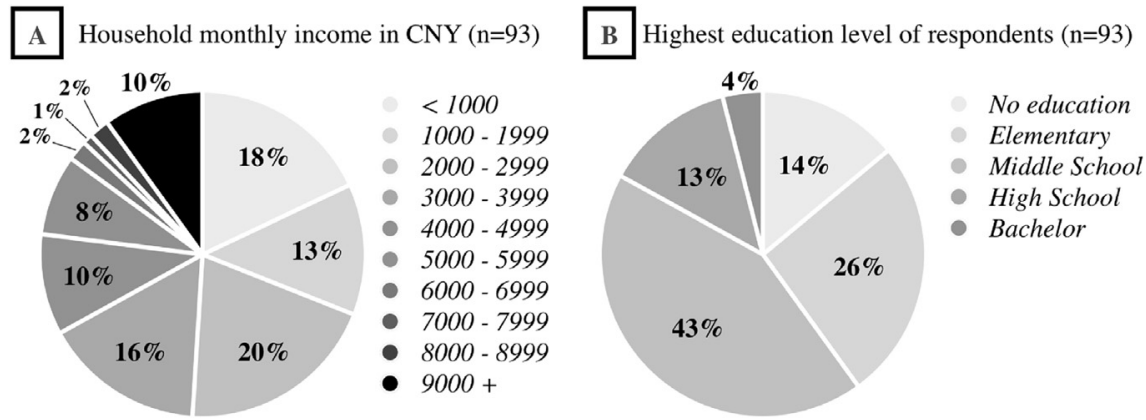

Fig. 4. A: Income distribution of all respondents B: Education distribution of all respondents. 
A What happens with respondents' trash \& waste $(\mathrm{n}=93)$

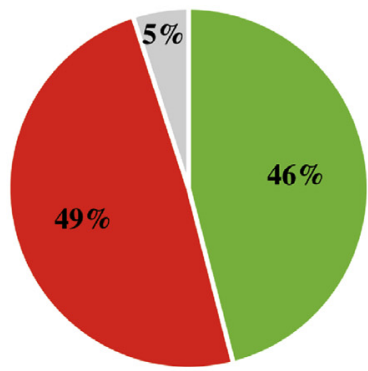

- Government takes care of it

- Throw it away or burn it themselves No answer
B $\%$ of total respondents $(\mathrm{n}=93)$ with health insurance

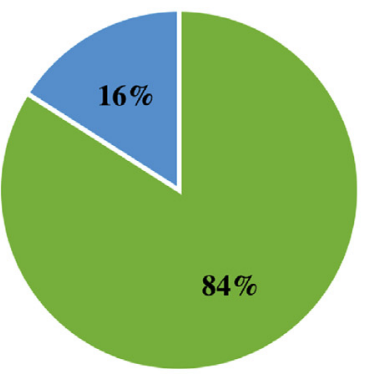

- Has health insurance

- No health insurance

Fig. 5. A: What happens to trash and waste of all respondents B: \% of all respondents that have health insurance.

In case of catastrophe, respondents $(\mathrm{n}=93)$ have...

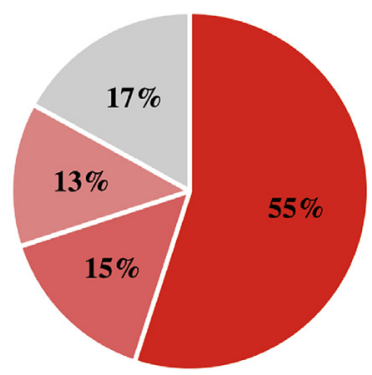

- neither

- family to rely on

- a job alternative both

Fig. 6. \% of total respondents that have possible job security or can rely on assistance from or shelter at relatives living elsewhere.

\subsection{Households affected by floods and pollution spills}

Flooding events pose an immediate threat to the population in terms of economic loss and risk of injury of death. During the survey, it is observed that some new houses in existing villages have a slightly elevated foundation to protect against (pluvial) floods (Fig. 3B). We have inquired the interviewees about the prevalence and origins of these floods. $29 \%$ of all respondents have indicated that they have been affected by flood (Fig. 7A), of which $11 \%(n=3)$ monthly, $67 \%$ annually, $22 \%$ once per decade. $37 \%$ of the people that farm a crop have ever been affected by floods. When asked about the origin of the floodwater, the majority of respondents (67\%) have answered from pluvial events, while $22 \%$ answered from the sea through storm surges, and $11 \%(n=3)$ answered that the flood originated from the river.

Pollution incidents and spills have a direct effect (e.g. death of crops) or indirect (consumption of contaminated nutrients or exposure) on the socio-ecologic component of deltas. It is observed that oil pumpjacks, large pipelines, and chemical plants are located throughout the Yellow River Delta, also in natural areas and adjacent to residences (Fig. 7B). 33\% of the interviewees have indicated that they are affected by chemical or oil spills (Fig. 7A). Of all respondents that are affected by pollution events, $27 \%$ indicated that they are regularly affected (weekly or more often) by chemical or oil pollution events. $53 \%$ of all respondents answered that they are affected on a monthly basis, while a remaining $20 \%$ answered pollution affects them on a yearly basis. As for the origin of these pollution events, a vast majority of respondents that indicated they are affected by oil spills from nearby chemical plants or factories. 1 respondent pointed to the nearby oil pumps as the culprit, while $10 \%$ did not provide an answer.

\subsection{Crops farmed and related hazards faced by farmers}

Agriculture, livestock, and aquaculture activities play an important role in the livelihood of the rural population in the Yellow River Delta. Yet, as presented before, not many respondents answered 'farmer' to the question: 'What is your job'. It soon became clear that the answer to the question 'what is your job' does not necessarily correspond to whether the respondents farm crops or not. In fact, a total of $74 \%$ of all respondents farm crops, hold livestock, or have aquaculture activities (see Fig. 8A). Agri-, and aquaculture activities are mostly conducted (by $93 \%$ of the respondents that either farm crop, hold livestock, or do aquaculture activities, $n=68$ ) on a small scale (e.g. limited to family employees or for feeding the family) with, presumably, little economic gain.

A mere $4 \%$ of those interviewed indicated that their agri- and aquaculture activities are conducted on a community scale with economic gain, and 3\% provided no answer. We asked all respondents what they farmed. Most farmers farm a variety of crops, livestock, or aquaculture. Of all respondents, crops are farmed most frequently $(63 \%, n=59)$, of which cotton ( $88 \%)$, maize $(42 \%)$ and soybeans $(20 \%)$ are the most common crops. $15 \%(n=12)$ of all respondents engages in farming livestock, of which $67 \%$ farm poultry (chickens or ducks) and $50 \%$ farm pigs. Aquaculture is conducted by $15 \%(n=12)$ of all respondents, of which $67 \%$ farm fish, 50\% farm shrimp, $25 \%$ farm crabs, and a single respondent ( $8 \%$ ) farms sea cucumbers. The majority (84\%) of the respondents are occupied with either crop, livestock, or aquaculture farming. See also Fig. 8B.

Poor ground water table management practices, as well as clearing of natural buffer areas between ocean and agricultural areas, leads to land degradation through salinization (Anthony, 2014; Fan et al., 2012; Syvitski, 2008; Vandenbohede et al., 2008). Agricultural land degradation is exacerbated by overuse (e.g. potassium fertilizers, or excessive irrigation practices). From all the respondents that farm crops, we have asked whether they suffer from salinization and drought. Salinization is a major issue for $79 \%$ of the respondents, while $16 \%$ do not suffer from drought or salinity (Fig. 9). Meanwhile, 59\% of the respondents who farm suffer from droughts; this may be attributed to the large percentage of cotton farmers, a crop that uses a relatively large amount of water (Davis, 2003). Regarding the irrigation method used by the farmers, $61 \%$ of the respondents have indicated hoses and sprinklers, while $22 \%$ of 
A

otal $\%$ of respondents $(n=93)$ that

suffer floods or oil/chemical spills

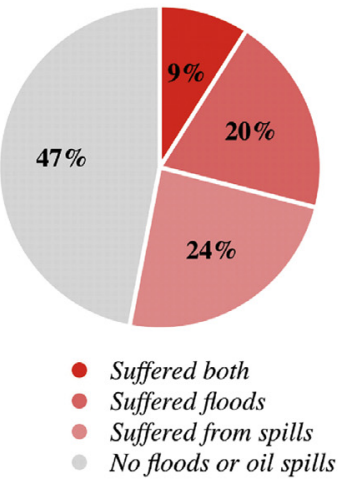

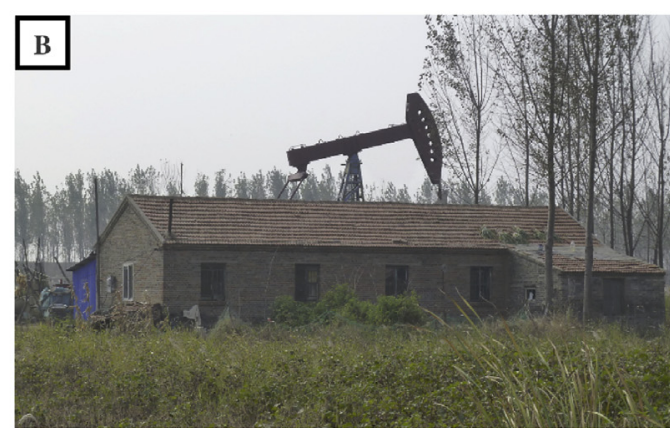

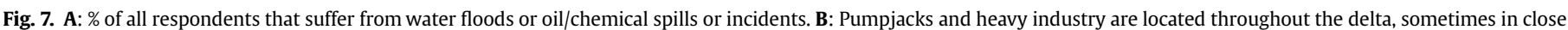
proximity to villages.

A

Distribution of total \% respondents $(n=93)$ that farm crops, livestock, aquaculture, a combination of the three, or nothing at all.*

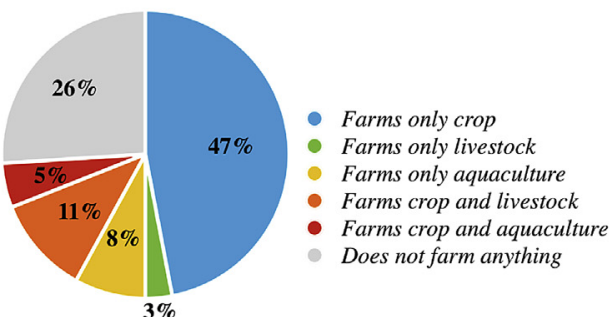

* None of the respondents farm a combination of 'crops, livestock, and aquaculture', or 'livestock and aquaculture'

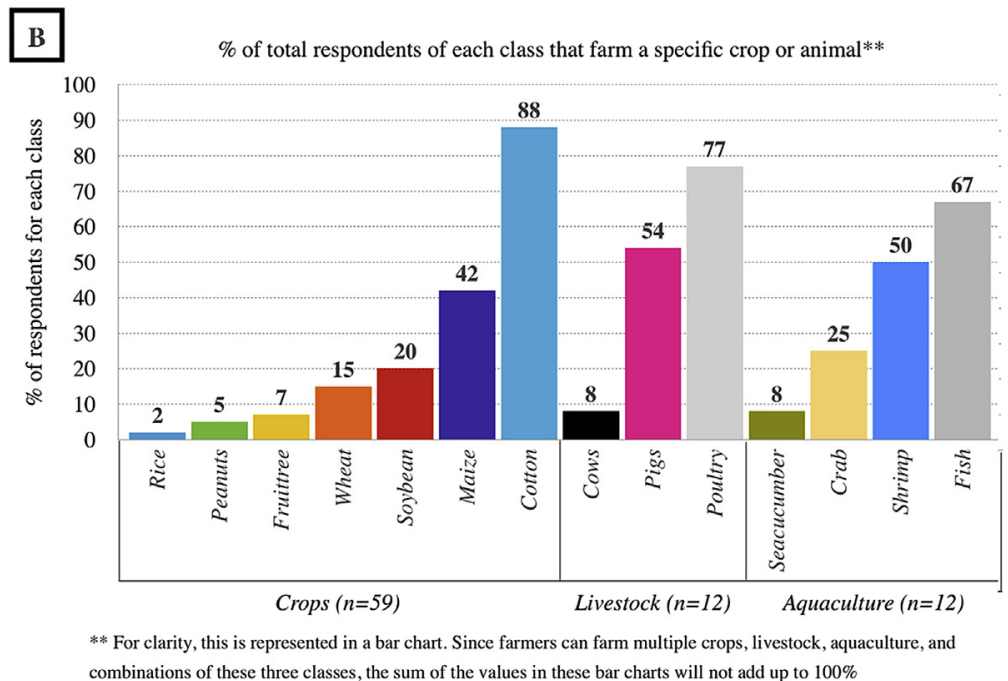

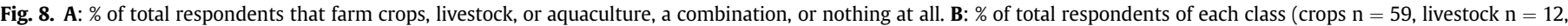
aquaculture $n=12$ ) that farm a specific crop or animal.

the respondents rely only on precipitation. $17 \%$ of the respondents did not answer. As for the surface water used for the hoses and sprinklers, the respondents mentioned three different sources: a majority (70\%) uses river water, while $19 \%$ rely on canal water, and $11 \%$ rely on reservoir water.

Total $\%$ of farming respondents $(\mathrm{n}=61)$ that suffer from drought or salinity

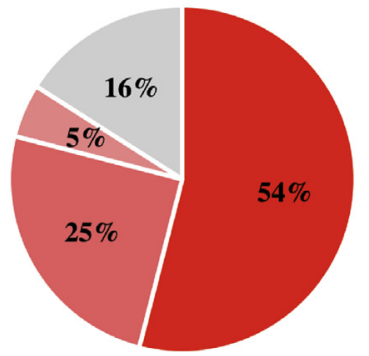

- Suffers drought and salinity

- Suffers from salinity

- Suffers from drought

No drought or salinity

Fig. 9. \% of respondents that farm crops or livestock something $(n=61)$ and suffer from drought or salinity.

\subsection{Awareness and opinions regarding climate change and pollution}

Besides the rural populations' access to facilities and rate of exposure to threats, it is also important to inquire about the awareness of the rural population to threats. The Yellow River Delta and its inhabitants are vulnerable to relative sea level rise due to its low geography and subsidence due to natural resource extraction (Higgins et al., 2013). Meanwhile, climate variability can lead to changed weather patterns (droughts and pluvial floods). The respondents were asked if they are aware of climate change and sea level rise, and the potential threats these have on the Yellow River Delta. 35\% of the respondents indicated that they heard about these processes (Fig. 10A). When asked to give their opinion about surface water, drinking water, and air pollution, the majority of respondents expressed concern (86\%, $80 \%$, and $85 \%$ respectively).

The respondents were also asked where they prefer to live in relation to potential hazardous areas, such rivers, coasts (due to floods) and factories (pollution) or urban areas, see also Fig. 10B. $42 \%$ want to live close to the river, and $47 \%$ want to live near the coast. $20 \%$ of the respondents want to live far away from rivers and coasts, while $38 \%$ have no preference to live close to rivers and $33 \%$ 

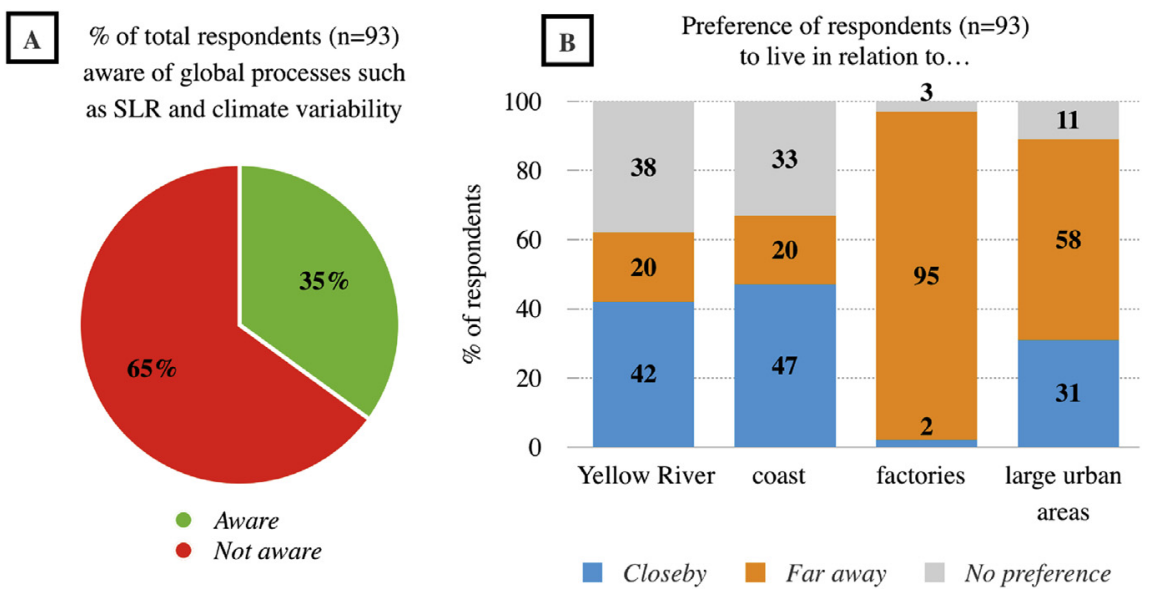

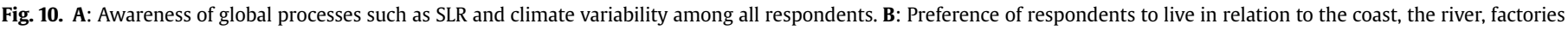
and large urban areas.

have no preference to live close to coasts. Results show that preference to living far or close to coasts related to knowledge of SLR. Of all 18 respondents that wanted to live far away from coasts, only 2 indicated they knew about SLR. Regarding to whether the respondents want to move near urban centers, $31 \%$ of the respondents preferred to live near (within urban areas or suburban), while $58 \%$ prefer to live outside of urban areas (villages, towns), while the rest did not state a preference. Virtually all respondents (95\%) do not want to live near factories.

\section{Discussion}

This is the first major household survey conducted under the local rural population in the Yellow River Delta, an area that despite heavy industry and large urban centers contains large agri- and aquaculture areas, while it is under threat of external and internal processes (SLR, salinization, pollution incidents etc.). Using data from the national statistics bureau in China, we have calculated that at least 100 samples are necessary to get a representative result. However, this is based on the total rural population of Dongying prefectural city, while the survey has focused on particular coastal sites around the Yellow River Delta, which is intersected by different municipalities. There is no data available considering population or number of rural households for these areas alone. Another challenge encountered during this survey is the sampling method used, because of available transport (sedan) which limited the survey extent due to poor infrastructure, and the distance between villages in different areas of the delta. Both the convenience sampling and the relatively few respondents mean that the survey results do not necessarily reflect the actual situation of the rural population in the Yellow River Delta. This affects the representativeness of the results, such as regarding the migrant status among the rural population. For example when analyzing access to facilities between migrants and non-migrants, there was no clear distinction between local population and migrants if one group has more access to facilities, social security, alternative jobs in case of catastrophes, as is suggested by studies such as Wang et al. (2012). However, the goal of this survey is exploratory, since there is little existing data (such as household number, threats endured by the population, migrant status, access to facilities of different populations etc.) available to create an attuned household survey.

It was expected that the majority of respondents are primarily concerned with farming crops and aquaculture, however, the majority of respondents identified themselves as manager despite that the respondents could provide multiple answers considering occupation. Nevertheless, many respondents have answered they are occupied with agri- and aquaculture activities when asked which crop (or livestock) they farmed. It remains unclear whether these activities are a primary or secondary source of income, or are conducted for personal consumption, furthermore considering that the most farmed crop is a cash crop: cotton. The results show that agriculture in the delta is conducted on small-scale family farms. However, we observed several unmarked migrant settlements within large agricultural areas outside village boundaries, which could indicate larger scale collective farming. The research team was unable, or not allowed, to conduct questionnaires in these migrant settlements.

During the survey, it is observed that villages are replaced by modern, concentrated urban areas, and that agricultural areas are undergoing large soil remediation efforts and reorganization, presumably to reinvigorate the soil and intensify agriculture activities, while improving the livelihood and living standards of inhabitants of the villages that are replaced. Therefore, the observed situation regarding small-scale family farming could change once these adaptations are completed in the future.

Results show that crops in the delta are irrigated with hoses and sprinklers using surface water. Yet a majority of the respondents indicated that they are suffering from droughts and salinization, which could be attributed to a shortage of usable surface water, insufficient water allocation for farmers, overuse of farmland, and seawater infiltrating into groundwater aquifers underneath agricultural lands. The household survey presented here could not reveal which of these processes are threatening agriculture activities, although future studies could include questions if the rural population is aware of such processes and water management policies and how this adversely affects the land usability.

The interviewers have encountered few fishermen, as there are strong indications (through conversations with respondents) that a certain percentage of fishermen are living exclusively on their boats and are thus not accessible by the interviewers. This questionnaire did not make a distinction between different classes of fishermen (boat dwelling, village dwelling, sea fishermen, inland water body fishermen), while managing to survey few fishermen overall.

The results of the survey also show that livelihood based on aquaculture are less widespread than anticipated, despite the fact that there are many aquaculture ponds in the Yellow River delta, especially to the east of Dongying-Kenli (Area 3 in Fig. 1). There were several migrant houses in these large aquaculture areas, which could suggest that aquaculture is based on temporary (migrant) labor and is largely done on an industrial scale. 
Concerns about pollution are widespread among the respondents, and the adversity to live in proximity to industrial areas is very high. Yet, a majority of respondents wants to live in proximity of the Yellow River (or does not care), despite the fact that the Yellow River is heavily polluted (Berry, 2012; Xu et al., 2004). This is probably because many people suffer from drought and salinity and are in need of water, but due to limited amounts because of water quotas and dried up ground water aquifers, turn to the Yellow River instead. Simultaneously many people report pluvial flooding. These observations suggest that usable water is scarce in the Yellow River Delta, and that the livelihoods of the rural population is at risk because of inadequate water management. The results also show that a majority of people are not aware of climate change and have a generally low level of education, and farm water intensive crops such as cotton, making these problems worse. However, it is observed during the survey that the Yellow River Delta is undergoing significant changes, with constructions of new population centers and revitalization of agricultural lands, with the goal to improve rural livelihoods and reducing vulnerability to droughts, pollution, salinization and other threats. It remains to be seen whether these improvements and reorganization efforts reach their goal.

As with any household survey, the respondents, interviewers, and questionnaire itself affect the results. For example, the results show that many, but not all, respondents suffer from floods and chemical or oil spill incidents. Yet, these results do not necessarily show whether the population is vulnerable to these events. If a household never experienced pluvial flooding, they might not perceive it as a threat, but they can still be vulnerable to such an event. A household might also perceive that it is very vulnerable to a specific threat, but that perception is unjustified due to superior protection (e.g. a newly constructed dyke next to the coast that a household might not be aware of yet). Additionally, this survey is conducted in the autumn (October 2013), which influences the questionnaire results. Different crops grow in different seasons, alternative irrigation methods depend on precipitation rates, and the repercussions of seasonal hazards affect the opinions of the respondents. For example, in the rainy season, respondents might worry more about pluvial flooding than in the dry season. These are the limitations of any household survey, although such information can be shown by means of cadastral maps, inspections of protective measures, and to an extent through earth observation, none of which was available during the survey period. The survey does provide information regarding historic and recurring events, which may not be revealed by the aforementioned data, as well as information regarding the awareness and opinions of the respondents, which can be used by local governments, policy makers etc. as indicators where awareness campaigns or additional mitigation efforts might be necessary.

\section{Conclusion}

The goal of this research was to assess the vulnerability to hazards, awareness of threats, and access to utilities and facilities (hospitals, transportation methods) of the rural population in the Yellow River Delta. Data considering the vulnerability to internal and external processes is known about the Yellow River Delta, although it is not known to what extent the rural population is vulnerable to and aware of it. This is the first household survey ever undertaken in the area and has an exploratory purpose, whose results can be used for attunement of future household surveys and assessments of vulnerability. The survey covers a variety of topics regarding jobs, income, education, facilities available, agri- and aquaculture activities, threats endured, awareness of climate change and sea level rise, as well as preference of living area. No detailed data is available considering the amount of rural households in the Yellow River Delta area, only for Dongying prefectural city as a whole (estimated at 358K). The Yellow River Delta is intersected by multiple municipalities where only the total population (rural and urban combined) is known, which makes it hard to make an estimate of the total households in the area of interest (taking into account mostly unregistered migrant populations). Due to the size of the delta and the travel time between the different villages in the delta, 93 households are incorporated in the survey, which is deemed sufficient for the exploratory nature of this survey.

The mean monthly income per household of the rural population in the Yellow River Delta is on par with the minimum wage for Dongying prefectural city in 2014, if it is assumed that households generally have 2 providers. However, more than 50\% of the households earn under $3000 \mathrm{CNY}$ (478 USD) close to the minimum wage for households in Dongying prefectural city, which means that the rural population has few monetary reserves in case of an emergency. The results show that a majority of the respondents has access to utilities such as electricity and water, and that drinking water supply is of no concern for most (83\%). A large majority of the respondents are covered by a healthcare plan (84\%), something that does not appear to be related to the migrant status of the respondent. In case of an evacuation, most respondents (67-70\%) have no alternative locations to go to or job alternatives in case their livelihood is lost. Thus, in case of a threat wherein many people lose their livelihood or their place of residence, many people are vulnerable as they cannot evacuate and have no job alternatives. The education level in the Yellow River Delta is low, with $82 \%$ not having finished high school. Awareness of climate change and sea level rise is similarly low, with only $35 \%$ of the respondents being aware of these processes. Waste management services is not accessible to a significant amount of respondents, with $48 \%$ of the respondents simply dumping or burning the trash, which causes pollutants to enter the environment that could possibly endanger populations and ecosystem health. These aspects make the rural population more vulnerable to processes such as climate variability, sea level rise, and water contamination due to pollutants. Increased awareness about the repercussions of the actions of the population, as well as raising awareness about global processes, might help the rural population to adapt.

Most of the respondents have indicated that their main occupation is manager, although a majority of the respondents (74\%) are engaged in agri- or aquaculture activities. Cotton and maize are amongst the most heavily farmed crops in the Yellow River Delta, while a minority of people hold livestock or conduct aquaculture. Virtually all farms are on a family scale (i.e. small sized with probably low economic gain). It is assumed that aquaculture is mostly conducted by people that do not live in the rural areas, which would explain the low amount of respondents that are working in the aquaculture sector, despite the aquaculture sector being widespread in certain parts of the Yellow River Delta.

Different threats affect the local rural population in the Yellow River Delta, such as floods and pollution spills. The survey results show that while a sizeable amount of respondents suffer from pluvial floods and pollution events from oil pumps, around $2 / 3{ }^{\text {rd }}$ of the respondents have not experienced such events. This does not necessarily mean that the other respondents are not vulnerable to these threats, as they might not have experienced such events but may still be at risk. Many of the respondents are farmers, whose crops mostly consist of cotton and maize. A majority of the farmers suffer from salinization and drought, which might indicate an alternative allocation of water resources or insufficient and degraded surface water. The cause for these water supply hazards shows promise for further studies. Another threat that affects the 
rural population is water, ground, and air pollution. The majority of respondents indicate they are concerned about the effects of pollution on their health or livelihood.

While this comprehensive survey reveals interesting details concerning crops farmed; facilities and utilities available; and threats faced by the local population, it is recommended that a follow-up study survey is conducted. Since the Yellow River Delta undergoes major changes (such as erosion and accretion rates, agriculture intensification, new infrastructure and urban center development), the rate of vulnerability of the rural population will undergo similar change. Future studies amongst a larger sample size over different seasons should provide results that are more representative with a smaller margin of error, since the answers of the respondents can be influenced depending on the season, weather conditions, lack of awareness to hazards and so on. The results of this questionnaire can be used to attune the questions of such a follow-up study, which has a larger sample size and a smaller margin of error. The opinion of the rural population about their vulnerability to various hazards is useful for future studies, as such a result can be compared to an in-depth analysis of social vulnerability of the Yellow River Delta by means of combining different types of data, such as statistical (e.g. census) and spatial data (e.g. earth observation). The results of vulnerability assessments that are based on those types of data can then be compared to the results of future household surveys, and to recommend and evaluate mitigation efforts that are used to improve the livelihood, level of awareness, and safety of the rural population in the Yellow River Delta.

\section{Acknowledgments}

The research for this article has been undertaken in the context of the DELIGHT project (Delta Information System for Geoenvironmental and Human Habitat Transition), which is funded by the Germany Ministry of Education and Research, BMBF. We would like to thank Juliane Huth for discussions on this paper. We are thankful to the anonymous reviewers providing helpful insights and comments that greatly helped to improve the manuscript.

\section{References}

Anthony, E.J., 2014. Deltas. In: Masselink, G., Gehrels, R. (Eds.), Coastal Environments and Global Change, first ed. John Wiley \& Sons, Hoboken, New Jersey, pp. 299-377.

Berry, B., 2012. River health and environmental flow in China project, background report for the yellow river. In: Berry, B. (Ed.), Australia-China Environment Development Partnership Brisbane, Australia, p. 83.

Bi, N., Wang, H., Yang, Z., 2014. Recent changes in the erosion-accretion patterns of the active Huanghe (Yellow River) delta lobe caused by human activities. Cont. Shelf Res. 90, 70-78.

Davis, T., 2003. Agricultural Water Use and River Basin Conservation, Living Waters (DJEnvironment, UK).

Fan, X., Pedroli, B., Liu, G., Liu, Q., Liu, H., Shu, L., 2012. Soil salinity development in the yellow river delta in relation to groundwater dynamics. Land Degrad. Dev. 23, 175-189.

Guobin, F., Shulin, C., Changming, L., 2004. Water crisis in the Huang Ho (Yellow) river: facts, reasons, impacts, and countermeasures. In: 7th International River Symposium, Brisbane, Australia.

Higgins, S., Overeem, I., Tanaka, A., Syvitski, J.P.M., 2013. Land subsidence at aquaculture facilities in the Yellow river delta, China. Geophys. Res. Lett. 40, 3898-3902.

IMHEN, Ca, Mau Peoples Committee, Kien Giang Peoples Committee, 2011. Climate change impact and adaptation study in the mekong Delta: climate change vulnerability and risk assessment study for Ca Mau and Kien Giang Provinces, Vietnam - final report. In: Mackay, P., Russell, M. (Eds.), Climate Change Vulnerability and Risk Assessment Study for Ca Mau and Kien Giang Provinces, Vietnam. Asian Development Bank, Melbourne, Australia.

Israel, G.D., 1992. Determining sample size, program evaluation and organizational development. Inst. Food Agric. Sci. 1-5.

Jiang, Y., 2009. China's water scarcity. J. Environ. Manag. 90, 3185-3196.

Kuenzer, C., Klein, I., Ullmann, T., Georgiou, E., Baumhauer, R., Dech, S., 2015. Remote sensing of river delta inundation: exploiting the potential of coarse spatial resolution, temporally-dense MODIS time series. Remote Sens. 7, 8516-8542.

Kuenzer, C., Ottinger, M., Liu, G., Sun, B., Baumhauer, R., Dech, S., 2014. Earth observation-based coastal zone Monitoring of the yellow river delta: dynamics in China's second largest oil producing region observed over four decades. Appl. Geogr. 53, 354-368.

Kuenzer, C., Quoc Vo, T., 2013. Assessing the ecosystem services value of can Gio Mangrove biosphere reserve: combining earth-observation- and householdsurvey-based analyses. Appl. Geogr. 45, 167-184.

Kuenzer, C., Renaud, F.G., 2012. Climate and environmental change in river deltas globally: expected impacts, resilience, adaptation. In: Renaud, F.G., Kuenzer, C. (Eds.), The Mekong Delta System: Interdisciplinary Analyses of a River Delta. Springer, Dordrecht, Netherlands, pp. 7-46.

Mmom, P.C., Aifesehi, P.E.E., 2013. Vulnerability and resilience of Niger Delta coastal communities to flooding. IOSR J. Humanit. Soc. Sci. 10, 27-33.

National Bureau of Statistics of China, 2013a. China Statistical Yearbook 2013. China Statistics Press, Beijing, China.

National Bureau of Statistics of China, 2013b. Shandong Statistical Yearbook 2013. China Statistics Press, Beijing, China.

Ottinger, M., Kuenzer, C., Liu, G., Wang, S., Dech, S., 2013. Monitoring land cover dynamics in the Yellow River Delta from 1995 to 2010 based on Landsat 5 TM. Appl. Geogr. 44, 53-68.

Overeem, I., Syvitski, J.P.M., 2009. Dynamics and vulnerability of delta systems. In: Overeem, I., Syvitski, J.P.M. (Eds.), Core Project of the International Geospherebiosphere Programme (IGBP) and the International Human Dimensions Programme on Global Environmental Change (IHDP). GKSS Research Center, p. 54. Geesthacht.

Quoc Vo, T., Kuenzer, C., Oppelt, N., 2015. How remote sensing supports mangrove ecosystem service valuation: a case study in ca Mau province, Vietnam. Ecosyst. Serv. 14, 67-75.

Renaud, F.G., Syvitski, J.P.M., Sebesvari, Z., Werners, S.E., Kremer, H., Kuenzer, C. Ramesh, R., Jeuken, A., Friedrich, J., 2013. Tipping from the Holocene to the Anthropocene: how threatened are major world deltas? Curr. Opin. Environ. Sustain. 5, 644-654.

Syvitski, J.P.M., 2008. Deltas at risk. Sustain. Sci. 3, 23-32.

Turner 2nd, B.L., Kasperson, R.E., Matson, P.A., McCarthy, J.J., Corell, R.W., Christensen, L., Eckley, N., Kasperson, J.X., Luers, A., Martello, M.L., Polsky, C. Pulsipher, A., Schiller, A., 2003. A framework for vulnerability analysis in sustainability science. Proc. Natl. Acad. Sci. U. S. A. 100, 8074-8079.

Vandenbohede, A., Houtte, E., Lebbe, L., 2008. Sustainable groundwater extraction in coastal areas: a Belgian example. Environ. Geol. 57, 735-747.

Wageindicator, 2014. China Minimum Wages 2013-2014.

Wang, M.-Z., Amati, M., Thomalla, F., 2012. Understanding the vulnerability of migrants in Shanghai to typhoons. Nat. Hazards 60, 1189-1210.

Wilk, J., Kgathi, D., 2007. Risk in the okavango Delta in the face of social and environmental change. GeoJournal 70, 121-132.

Wolters, M.L., Kuenzer, C., 2015. Vulnerability assessments of coastal river deltas categorization and review. J. Coast. Conserv. 19, 345-368.

Wu, Q., Xia, X., 2014. Trends of water quantity and water quality of the Yellow river from 1956 to 2009: implications for the effect of climate change. Environ. Syst. Res. 3, 6.

Xu, J., 2008. Response of land accretion of the Yellow river delta to global climate change and human activity. Quat. Int. 186, 4-11.

Xu, X., Lin, H., Fu, Z., 2004. Probe into the method of regional ecological risk assessment-a case study of wetland in the Yellow river Delta in China. J. Environ. Manag. 70, 253-262.

Yamane, T., 1967. Statistics, an Introductory Analysis, second ed. Harper and Row, New York, USA. 